\title{
Vasoactive Intestinal Peptide (VIP) and VIP Receptors-Elucidation of Structure and Function for Therapeutic Applications
}

\author{
Hisato Igarashi ${ }^{1}$, Nao Fujimori ${ }^{1}$, Tetsuhide Ito ${ }^{1}$, Taichi Nakamura ${ }^{1}$, Takamasa Oono ${ }^{1}$, \\ Kazuhiko Nakamura ${ }^{1}$, Koichi Suzuki ${ }^{2}$, Robert T. Jensen ${ }^{3}$, Ryoichi Takayanagi ${ }^{1}$ \\ ${ }^{1}$ Department of Medicine and Bioregulatory Science, Graduate School of Medical Science, Kyushu University, Fukuoka, Japan; \\ ${ }^{2}$ Lepropsy Research Center, National Institute of Infectious Diseases, Tokyo Japan; ${ }^{3}$ Digestive Diseases Branch, National Institute of \\ Diabetes and Digestive and Kidney Diseases, National Institutes of Health, Bethesda, USA. \\ Email: itopapa@med.kyushu-u.ac.jp
}

Received April $18^{\text {th }}, 2011$; revised July $15^{\text {th }}, 2011$; accepted August $18^{\text {th }}, 2011$.

\begin{abstract}
Vasoactive intestinal peptide (VIP) is a 28-amino acid polypeptide first isolated from swine duodenum. VIP is a neurotransmitter that is extensively distributed in tissues. According to published reports, VPAC1 and VPAC2 act as VIP receptors and are widely present in the central nervous system and peripheral tissues. VIP exerts diverse actions on the cardiovascular system, pancreas, digestive tract, respiratory system, and urological system. Recent reports indicated that VIP has immunological and neuroprotective effects and also affects cell growth. While primary investigations for developing therapeutic applications for various pathological conditions and diseases are underway, the structure and function of VIP should be analyzed in more detail.
\end{abstract}

Keywords: Vasoactive Intestinal Peptide, VIP, VPAC

\section{Introduction}

Vasoactive intestinal peptide (VIP) is a 28 -amino acid polypeptide that was first isolated from swine duodenum about 40 years ago. The polypeptide derived its name because of its vasodilating action, which modifies the intestinal blood flow [1]. VIP was first classified as an intestinal hormone because it was isolated from the digestive tract and plays a role in electrolyte secretion in the intestinal tract, but it was subsequently found to be extensively distributed as a neurotransmitter in tissues [2]. VIP derived from pigs, cows, and rats have the same structure. Furthermore, VIP released from endocrine cells in the central nerve, peripheral nerve, digestive tract, or pancreas has the same structure. VIP exerts neural modulating activity on secretion, gastrointestinal motility, and blood flow in the pancreas and intestine, and the peptide shows similar activities in the cardiovascular, respiratory, and urological systems [2]. Recent reports have described a broader range of activities, such as immunological and neuroprotective effects [2]. While preliminary investigations for the development of therapeutic applications for various pathological conditions and diseases are underway, the structure and function of the protein needs to be analyzed in greater detail for this purpose.

In this review, we have discussed current information on VIP and its receptors and included new findings.

\section{Structure of VIP}

Since the amino acid sequence of VIP is very similar to that of secretin and glucagon, it was formerly classified with these peptides in the secretin peptide family [2]. The structure of VIP is similar to that of numerous other peptides, including pituitary adenylate cyclase activity peptide (PACAP), peptide histidine isoleucine or methionine (PHI or PHM), growth hormone-releasing factor (GRF), and glucagon-like peptide (GLP) as well as non-mammalian helospectin I, helospectin II, helodermin, exendin-3, and exendin-4 (Figure 1). VIP has 70\% homology with PACAP27, with 19 amino acids in common, 50\% homology to PACAP38, with 9 amino acids in common, and 33\% homology with secretin. PHI, a VIP-related peptide, was isolated from swine small intestine, and along with PHM, it shares $48 \%$ amino acid homology 


\begin{tabular}{|c|c|c|c|c|c|c|c|c|c|c|}
\hline \multirow{2}{*}{ Homology (\%) } & \multirow{2}{*}{ peptide } & \multicolumn{9}{|c|}{ amino acid sequence } \\
\hline & & $\ldots 5$ & $\ldots 10$ & $\ldots 15$ & $\ldots 20$ & $\ldots 25$ & $\ldots 30$ & $\ldots 35$ & $\ldots 40$ & $\ldots 45$ \\
\hline 100 & VIP & HSDAV & FTDNY & TRLRK & QMAVK & KYLNS & ILN & & & \\
\hline 70 & PACAP27 & HSDGI & FTDSY & $\mathrm{SRY} \mathrm{YKK}$ & QMAVK & KYLAA & $\mathrm{vL}$ & & & \\
\hline 50 & PACAP38 & HSDGI & FTDsY & $\mathrm{SRYRK}$ & QMAVK & KYLAA & VLGKR & YKQRV & KNK & \\
\hline 48 & PHI & $\mathrm{H} \mathrm{A} \mathrm{D} \mathrm{GV}$ & FTSSDF & SRLLG & QLSA $\mathrm{K}$ & KYLES & LI & & & \\
\hline 33 & SECRETIN & HSDGT & FTSEL & SRLRD & SARLQ & RLLQG & LV & & & \\
\hline 21 & GLUCAGON & HSQGT & FTSDY & SKYLD & SRRAQ & DFVQW & $\mathrm{LMNT}$ & & & \\
\hline 20 & GRF & YADAI & FTNSY & RKVLG & QLSAR & KLLLD & IIMSRQ & QGESN & QERGA & RARL \\
\hline 18 & GLP-2 & $\mathrm{H} A \mathrm{D} \mathrm{GS}$ & $\mathrm{FS} D \mathrm{EM}$ & NTILD & NLAAR & DFINW & LIQTK & ITDR & & \\
\hline 17 & GLP-1 & HAEGT & FTSDV & SSYLE & $\mathrm{GQAAK}$ & EFIAW & LVKGR & & & \\
\hline
\end{tabular}

Figure 1. Amino acid sequences of vasoactive intestinal peptide (VIP) and glucagon-related peptides in mammals and the homologies of these sequences.

with VIP. PHI/PHM is produced by posttranslational processing of the VIP precursor, as discussed later [3].

When VIP was analyzed by circular dichroism (CD) or nuclear magnetic resonance (NMR) spectroscopy, it was shown to have a helical conformation with an $\alpha$-helix (residues 11 - 26) and $2 \beta$-bends (residues 2 - 5 and 1 10) at the N-terminus [4] (Figure 2). The N-terminal and C-terminal domains are believed to be important for bioactivity and receptor recognition.

Fifteen years ago, the human VIP gene was cloned and mapped to chromosome 6q25 (Figure 3) [2]. The human VIP precursor gene consists of 7 exons and 6 introns [3]. A signal peptide consisting of 21 amino acids is located in the second exon. PHM is encoded by the fourth exon, and VIP is encoded by the fifth exon; VIP and PHM are produced after processing [3].

While VIP is soluble in water and aqueous organic solvents, its activity is lowered by oxidization because of the inclusion of a methionine residue. An aqueous solution of VIP is relatively unstable. VIP is easily degraded as its half-life in vivo is less than $1 \mathrm{~min}$ [5].

\section{Structure of Receptor}

G protein-coupled 7 transmembrane receptors comprise the $\mathrm{G}$ protein-coupled receptor (GPCR) family and are classified into 3 groups (A, B, and C) [2]. The VIP/ PACAP receptor belongs to group B of the GPCR family and consists of 437 - 459 amino acid residues with an extracellular long-chain $\mathrm{N}$-terminal domain $(\geq 120$ amino acid residues). In the extracellular domain, an asparagine-linked glycosylation site is paired with the cysteine residue, and the first and second extracellular domains form a disulfide bond [6].

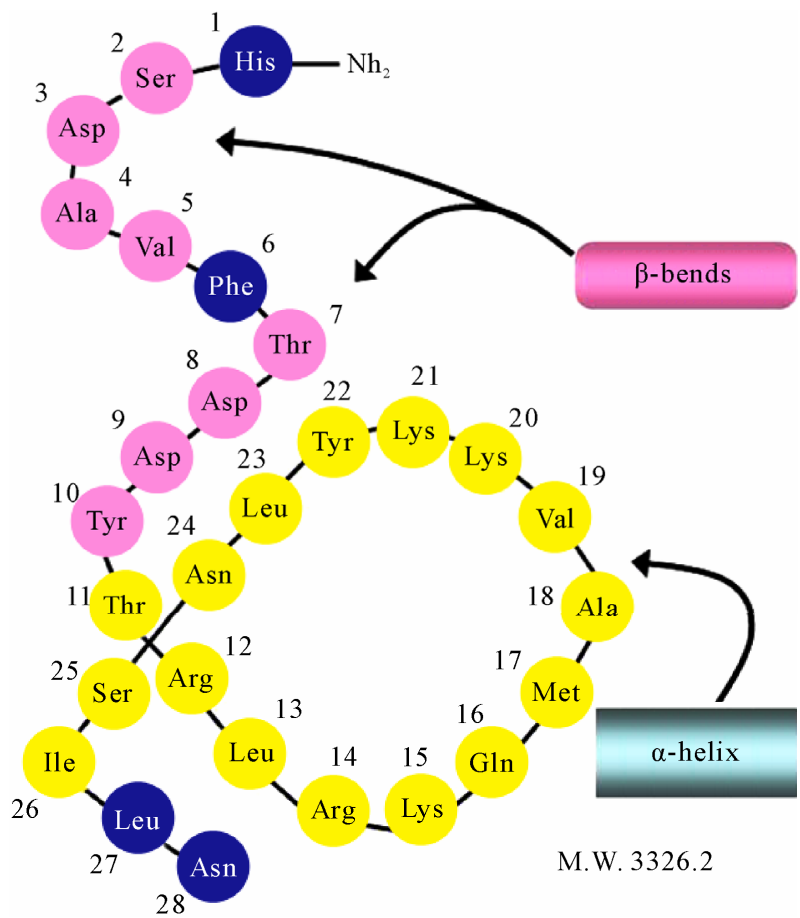

Figure 2. Secondary structure of VIP.

According to the IUPHAR (International Union of Pharmacology) Classification [7] issued in 1998 (Table 1), mammals have 2 subtypes of VIP receptors (VPACs), namely, VPAC1 and VPAC2.

Figure 4 shows the amino acid sequence and the GenBank accession number of human VPACs extrapolated from the nucleotide sequence. Human VPAC1 [8] and VPAC2 [9] have 457 and 438 amino acid residues, respectively. Rat VPAC1 [10] and VPAC2 [11] have 459 


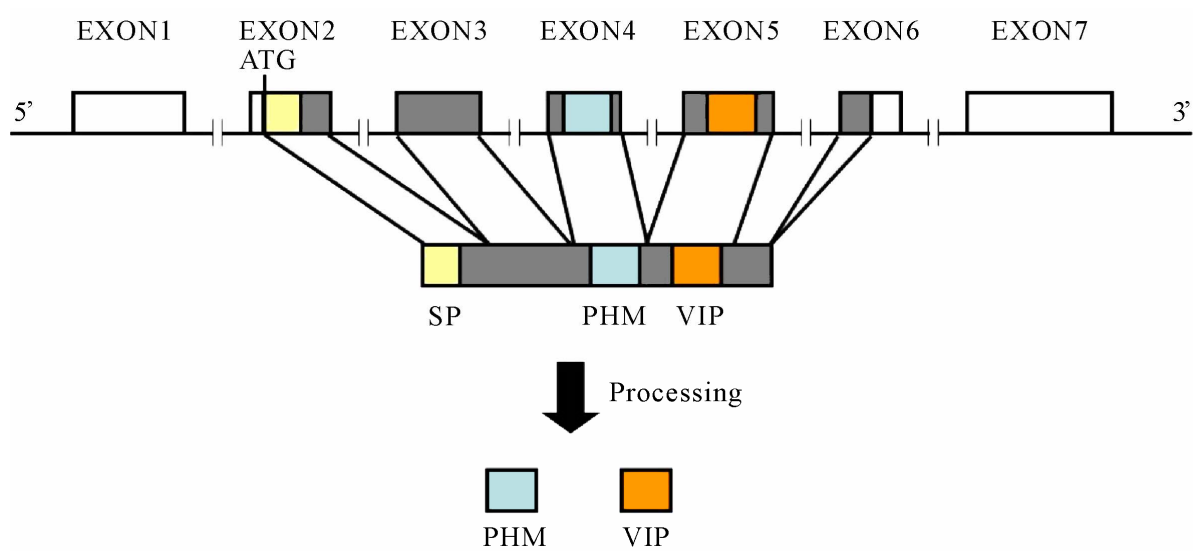

Figure 3. Structure of the human VIP precursor gene (The untranslated regions are shown in white, and the signal peptides are shown in yellow).

Table 1. Classification of pituitary adenylate cyclase activity peptide (PACAP) and vasoactive intestinal peptide (VIP) receptors.

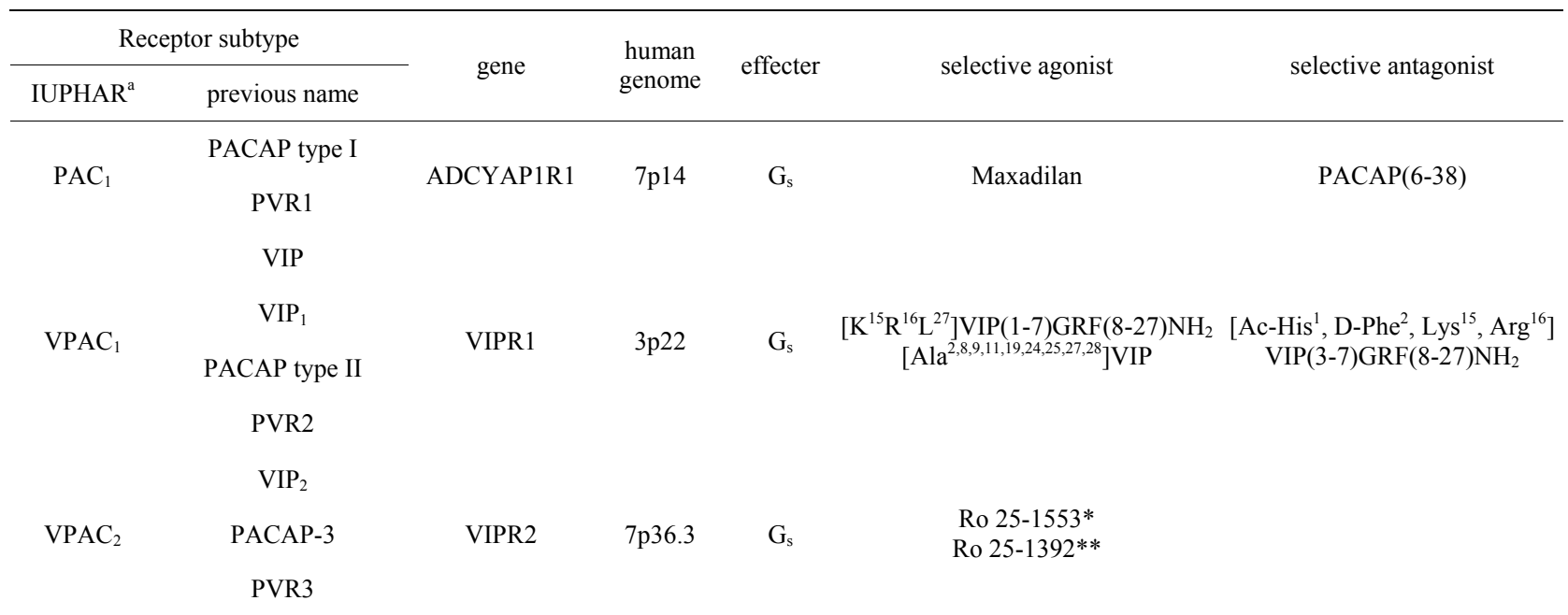

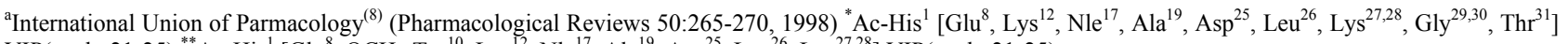
VIP(cyclo 21-25) ${ }^{* *} \mathrm{Ac}^{-\mathrm{His}^{1}}\left[\mathrm{Glu}^{8}, \mathrm{OCH}_{3}-\mathrm{Tyr}^{10}, \mathrm{Lys}^{12}, \mathrm{Nle}^{17}, \mathrm{Ala}^{19}, \mathrm{Asp}^{25}, \mathrm{Leu}^{26}, \mathrm{Lys}^{27,28}\right.$ ] VIP(cyclo 21-25).

\begin{abstract}
Human VPAC1 receptor (Genebank L13288, [9])
MRPPSPLPARWLCVLAGALAWALGPAGGQAARLQEECDYVQMIEVQHKQCLEEAQLE NETIGCSKMWDNLTCWPATPRGQVVVLACPLIFKLFSSIQGRNVSRSCTDEGWTHLEPG PYPIACGLDDKAASLDEQQTMFYGSVKTGYTIGYGLSLATLLVATAILSLFRKLHCTRNYIH MHLFISFILRAAAVFIKDLALFDSGESDQCSEGSVGCKAAMVFFQYCVMANFFWLLVEGL YLYTLLAVSFFSERKYFWGYILIGWGVPSTFTMVWTIARIHFEDYGCWDTINSSLWWIIKG PILTSILVNFILFICIIRILLQKLRPPDIRKSDSSPYSRLARSTLLLIPLFGVHYIMFAFFPDNFKPE VKMVFELVVGSFQGFVVAILYCFLNGEVQAELRRKWRRWHLQGVLGWNPKYRHPSGG SNGATCSTQVSMLTRVSPGARRSSSFQAEVSLV
\end{abstract}

Human VPAC2 receptor(Genebank L36566, [10]) MRTLLPPALLTCWLLAPVNSIHPECRFHLEIQEEETKCTELLRSQTEKHKACSGVWDNITC WRPANVGETVTVPCPKVFSNFYSKAGNISKNCTSDGWSETFPDFVDACGYSDPEDESKI TFYILVKAIYTLGYSVSLMSLATGSIILCLFRKLHCTRNYIHLNLFLSFILRAISVLVKDDVLYSSS GTLHCPDQPSSWVGCKLSLVFLQYCIMANFFWLLVEGLYLHTLLVAMLPPRRCFLAYLLIG WGLPTVCIGAWTAARLYLEDTGCWDTNDHSVPWWVIRIPILISIIVNFVLFISIIRILLQKLTS PDVGGNDQSOYKRLAKSTLLLIPLFGVHYMVFAVFPISISSKYQILFELCLGSFQGLVVAVLY CFLNSEVQCELKRKWRSRCPTPSASRDYRVCGSSFSHNGSEGALQFHRASRAQSFLQTET SVI

Figure 4. Amino acid sequence of human VPACs. and 437 amino acid residues, respectively, and the human and rat receptors share approximately 50\% homology. Similar to the rat receptor, mouse VPAC2 also consists of 437 amino acid residues [12].

Next, the pharmacological interactions between VIP and its receptors will be discussed. According to a study performed using pancreatic acinar cells isolated from guinea pigs, VPACs have two VIP-binding sites. Binding site 1 has a high affinity for VIP, and the equilibrium dissociation constant $\left(\mathrm{K}_{\mathrm{d}}\right)$ of the interaction is $0.21 \mathrm{nM}$.

Binding site 2 has a low affinity for VIP, and the $\mathrm{Kd}$ is $82.4 \mathrm{nM}$. According to an investigation with the VPAC2 agonist Ro25 - 1553 (Table 1), binding site 1 has a high affinity for Ro25 - 1553, and the $\mathrm{K}_{\mathrm{d}}$ is $0.36 \mathrm{nM}$, and the number of binding sites is $0.136 \mathrm{pmol} / \mathrm{mg}$ protein. In binding site 2, which has a low affinity for Ro25 - 1553, 
the $\mathrm{K}_{\mathrm{d}}$ is $2.94 \mathrm{nM}$, and the number of binding sites is 2.7 $\mathrm{pmol} / \mathrm{mg}$ protein [13]. Unlike guinea pig cells, rat pancreatic acinar cells have four binding sites, and therefore, the interactions are more complicated [14].

\section{Distribution of VIP and Receptors}

VIP is widely distributed at high concentrations in the digestive tract and nervous system. The tissue distribution of VIP is generally not different between species, but VIP activity levels differ depending upon the species. In the central nervous system, VIP is broadly distributed in the cerebral cortex and hypothalamus, and its distribution in the cortex of the frontal lobe, hippocampus, and the cortex of the optic area is especially abundant [15]. In the brain, VIP-containing neurons are observed in the ventromedial hypothalamic nucleus, including the arcuate nucleus, by fluorescent histochemistry. The axons of these neurons are distributed along the wall of the third ventricle, toward the nerve fibers of the vascular wall of the leptomeninges in the hypothalamic region. VIP-containing neurons are highly concentrated in the adrenal glands, salivary glands, and pancreas, and they are also found in the stomach, small intestine, and ascending colon [15]. As for VIP-containing neurons in the digestive tract, a great number of these nerve cell bodies and fibers are observed in the intermuscular region and submucosal plexus, and a dense network of these neurons exists in the lamina propria. Furthermore, VIP is also found in the nerve fibers of the sphincter region and in the nerves of the genitourinary organs.

The distribution of VPAC1 and VPAC2 has been extensively analyzed. VPAC1 is expressed in the liver, lungs, kidneys, prostate gland, mammary glands, spleen, lymphocytes, mucosa of the stomach and small intestine, and many other tissues [16]. In the central nervous system, VPAC1 is expressed in the cerebral cortex, piriform cortex, dentate gyrus, lateral amygdaloid nucleus, putamen, supraoptic nucleus, choroid plexus, and pineal body, and other regions [17]. VPAC2 is expressed in large amounts in the smooth muscle of organs and vascular walls and is also observed in the large intestinal mucosa, thyroid follicular cells, adrenal medulla, retina, and alveolar epithelium. In the central nervous system, VPAC2 is expressed in the cerebral cortex, olfactory brain, thalamus, hippocampus, amygdala, paraventricular cortex, etc. [17]. VPAC2 is also expressed in lymphocytes and macrophages after bacterial or viral infections [2]. The expression of VPACs in tumor cells and various cell lines has also been reported. According to previous report, VPAC1 is expressed in lung cancer, gastrointestinal cancer, pancreatic cancer, and hepatic cancer, while VPAC2 is expressed in leiomyomas and other cancers [2].

\section{VIP Agonists}

In order to analyze the functions of VIP, agonists and antagonists with strong receptor selectivity need to be studied. A previously published reports revealed the number of agonists with subtype selectivity [2] (Table 1). Using these agonists, the actions of VPAC1 and VPAC2 have been analyzed. Alanine scanning was used to identify the amino acids in VIP that were not essential for interaction with VPACs. All of these amino acids were replaced with alanine to create $\left[\mathrm{Ala}^{2,8,9,11,19,24,25,27,28}\right]$ VIP and $\left[\mathrm{Ala}^{2,8,9,11,19,22,24,25,27,28}\right]$ VIP analogs [18,19]. Since the easily degradable parts were replaced with alanine, these analogs showed greater stability while maintaining the same levels of selectivity [19]. We hope that these modified analogs will become the prototype for a therapeutic agent in the future. Although other agonists of VPAC1 and VPAC2 have been described [2], an antagonist with satisfactory selectivity and affinity has not yet been obtained; therefore, further studies need to be performed.

\section{Activities of VIP}

\subsection{Physiological Activities}

VIP is extensively distributed in central and peripheral tissues, where it acts as a neurotransmitter and neuromodulator [15]. VIP acts as neuromodulator of secretion, gastrointestinal motility, and blood flow in the pancreas and intestinal tract, and similar actions are generally observed in the cardiovascular, respiratory, and urological systems [15].

1) The main activity of VIP is vasodilatation, which is organ-specific. VIP induces dilation of peripheral vessels, intestinal vessels, coronary arteries, and the pulmonary artery, which results in increased blood flow, decreased peripheral vascular resistance, and hypotension. Furthermore, it increases the blood flow of the hepatic artery and pancreaticoduodenal artery to induce vasodilatation of hepatic and pancreatic vessels $[2,15]$. Since VIP has a vasodilatory action, the VIP derivative aviptadil is expected to become a new therapeutic agent for pulmonary hypertension [20].

2) While VIP has a suppressive effect on intestinal smooth muscle, it exerts relaxant effects on the lower esophageal sphincter, sphincter of Oddi, and anal sphincter. It also exerts a relaxant effect on bronchial smooth muscle.

3) In the small intestine, VIP facilitates the secretion of electrolytes and aqueous liquid. In the stomach, it inhibits gastric secretion.

4) In the pancreas, VIP facilitates external secretion of bicarbonic acid and aqueous liquid from pancreatic epithelial cells and facilitates enzyme secretion from acinar 
cells [13]. In an experiment conducted using pancreatic acinar cells isolated from rats and guinea pigs, about $90 \%$ of VIP-mediated enzyme secretion involved VPAC1 [13].

5) VIP promotes the secretion of both insulin and glucagon in a glucose-dependent manner [21]. While VPAC1 and VPAC2 are both expressed on endocrine cells, insulin secretion occurs mainly through VPAC2. VIP activity caused an increase in cAMP levels and activation of protein kinase A (PKA). Insulin secretion is accelerated by the direct action of PKA or by elevation of intracellular $\mathrm{Ca}^{2+}$ levels via the voltage-dependent $\mathrm{Ca}^{2+}$ channel [21] (Figure 5). Previously, a selective agonist of VPAC2 was reported to promote insulin secretion and improves glucose tolerance, thereby inducing hypoglycemia. Its potential as a therapeutic agent for type 2 diabetes is now being investigated [21].

6) VIP is broadly distributed in the central nervous system, especially in the hypothalamus and pituitary anterior lobe [22], and it is associated with the regulation of pituitary hormones. VIP acts in vivo as a prolactin (PRL)releasing factor that stimulates the release of the growth hormone (GH) [23].

Blood levels of VIP are low in obese women and high in patients with anorexia nervosa, which indicates that VIP is involved in PRL/GH secretory dysfunction in these 2 diseases [24].

7) According to one study performed using macro- phages, the VIP receptor functions to inhibit the production of inducible nitric oxide synthase (iNOS), inhibit the production of the proinflammatory cytokine tumor necrosis factor (TNF)- $\alpha$, and promote the production of the anti-inflammatory cytokine interleukin (IL)-10 [25]. These functions are known to be mediated by the suppression of nuclear transcription factor (NF- $\kappa \mathrm{B}$ ) activation [26]. Administration of VIP has been also reported to cause a remarkable improvement in joint disease in an experimental chronic rheumatoid arthritis model [27]. The mechanism was explained by VIP-mediated inhibition of Th1 and augmentation of Th2 in the cytokine balance. Because of its anti-inflammatory and immune-regulating actions, VIP application has been examined in experimental models for septic shock [28], Crohn's disease [29], acute pancreatitis [30], and hepatitis [31]. We have shown that acute pancreatitis in a mouse model is improved by the administration of VIP and a VPAC1 agonist, and we have also reported that this improvement is primarily mediated by inhibition of monocyte/macrophage-derived cytokine production via the VPAC1 [30].

8) Various diseases have been reported to involve VIP activity, including bronchial asthma [32], transmission of pain [33], cluster headache [34], Alzheimer's disease [35], Parkinson's disease [36], and brain injury [37]. In particular, the neuroprotective action of VIP has drawn attention, raising hopes for the use of VIP as a therapeutic

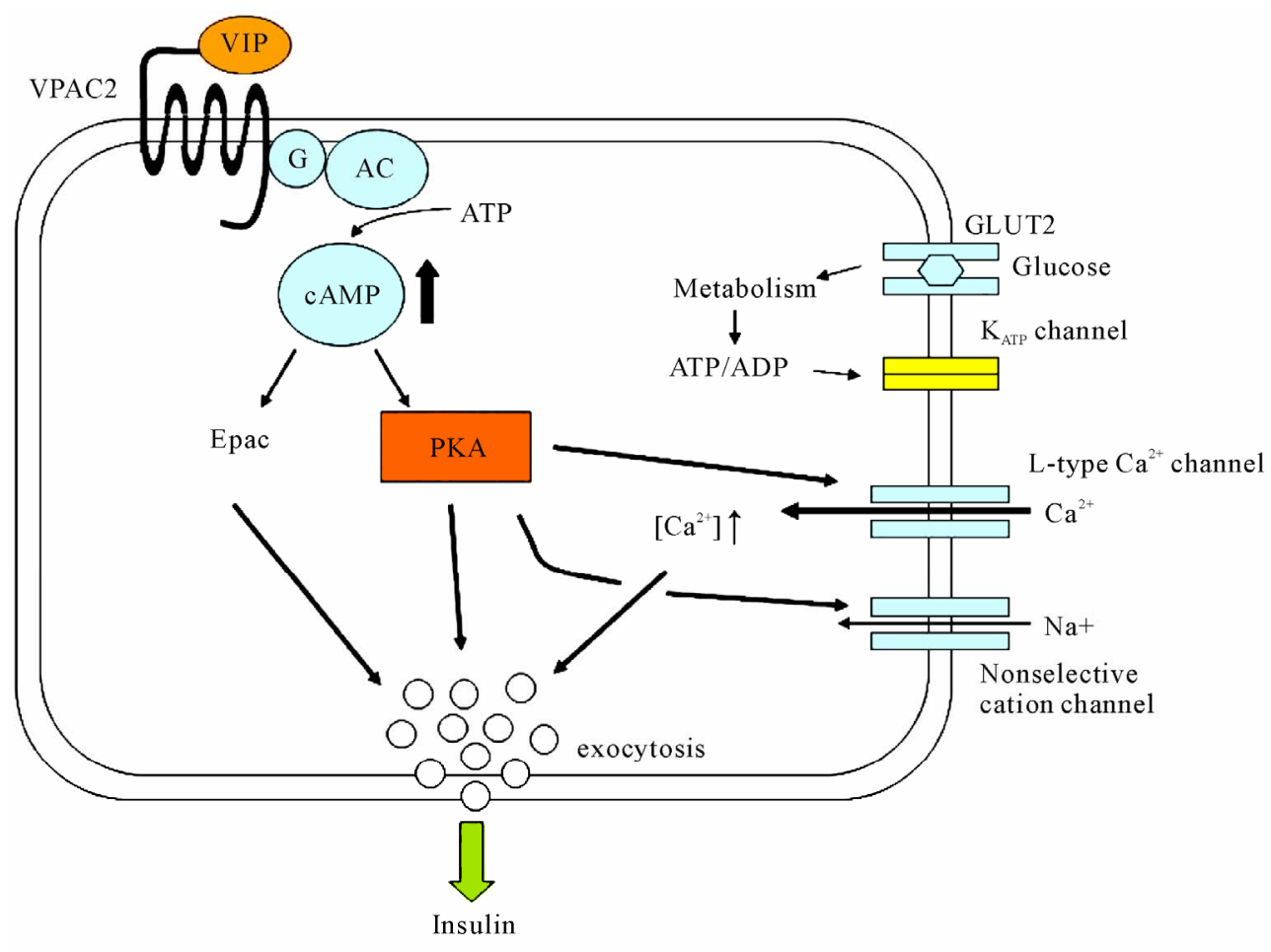

Figure 5. Insulin secretion signal from VIP. 
agent.

9) VIP acts as a growth factor [38]. According to several reports, it functions as a proliferative factor in normal tissue cells as well as in prostate cancer, breast cancer, lung cancer, pancreatic cancer, and other cancer cells [38-41]. Furthermore, VPAC1 antagonists inhibit the proliferation of breast cancer and lung cancer cells in vitro [40]. In the light of the VPAC1 overexpression in prostate and breast cancer, an experiment was performed using a VPAC1 agonist to visualize tumor localization [42].

10) VIP might inhibit apoptosis by stimulating the expression of the apoptosis-inhibiting gene $\mathrm{Bcl} 2$ or by inhibiting the activity of caspase 3 , which is a part of the caspase cascade [43]. VIP administration reportedly inhibited apoptosis in submandibular gland-derived acinar cells and neurinoma cells $[43,44]$.

\subsection{Clinical Trials}

Based on these functions of the peptide, several clinical trials have been reported using VIP or its analog for asthma [45] and sarcoidosis [46]. Linden et al. performed a double-blind, randomized, placebo controlled, crossover study for twenty four patients with moderate stable asthma [45]. They concluded that inhalation of a Ro25-
1553 constituted a promising approach for bronchodilation in patients with asthma. Prasse A, et al. reported their open clinical Phase II study where they treated twenty patients with histologically proved sarcoidosis with nebulized VIP for 4 weeks [46]. VIP inhalation significantly reduced production of tumor necrosis factoralpha by cells isolated from bronchoalveolar lavage CD4(+)CD127(-)CD25(+) T cells [46]. They concluded that inhalation of VIP might be developed into a new therapeutic principle for chronic inflammatory lung of humans. In the nearly future, VIP and VIP analog might be a candidate for a new therapeutic tool for other pathological condition.

\subsection{Signal Transduction}

By binding to ligand, VPAC acts on the Gs protein and activates PKA via elevation of adenylate cyclase activity and production of cAMP (cAMP-dependent pathway). PKA either inhibits phosphorylation of the downstream MAP/ERK kinase or promotes phosphorylation of cAMP response element binding protein (CREB), which finally leads to inhibition of NF- $\kappa$ B. Meanwhile, studies have also identified a pathway that inhibits nuclear entry of $\mathrm{NF}-\kappa \mathrm{B}$ through VPAC signaling, which inhibits $\mathrm{I} \kappa \mathrm{B}$ phosphorylation (cAMP-independent pathway). Figure 6

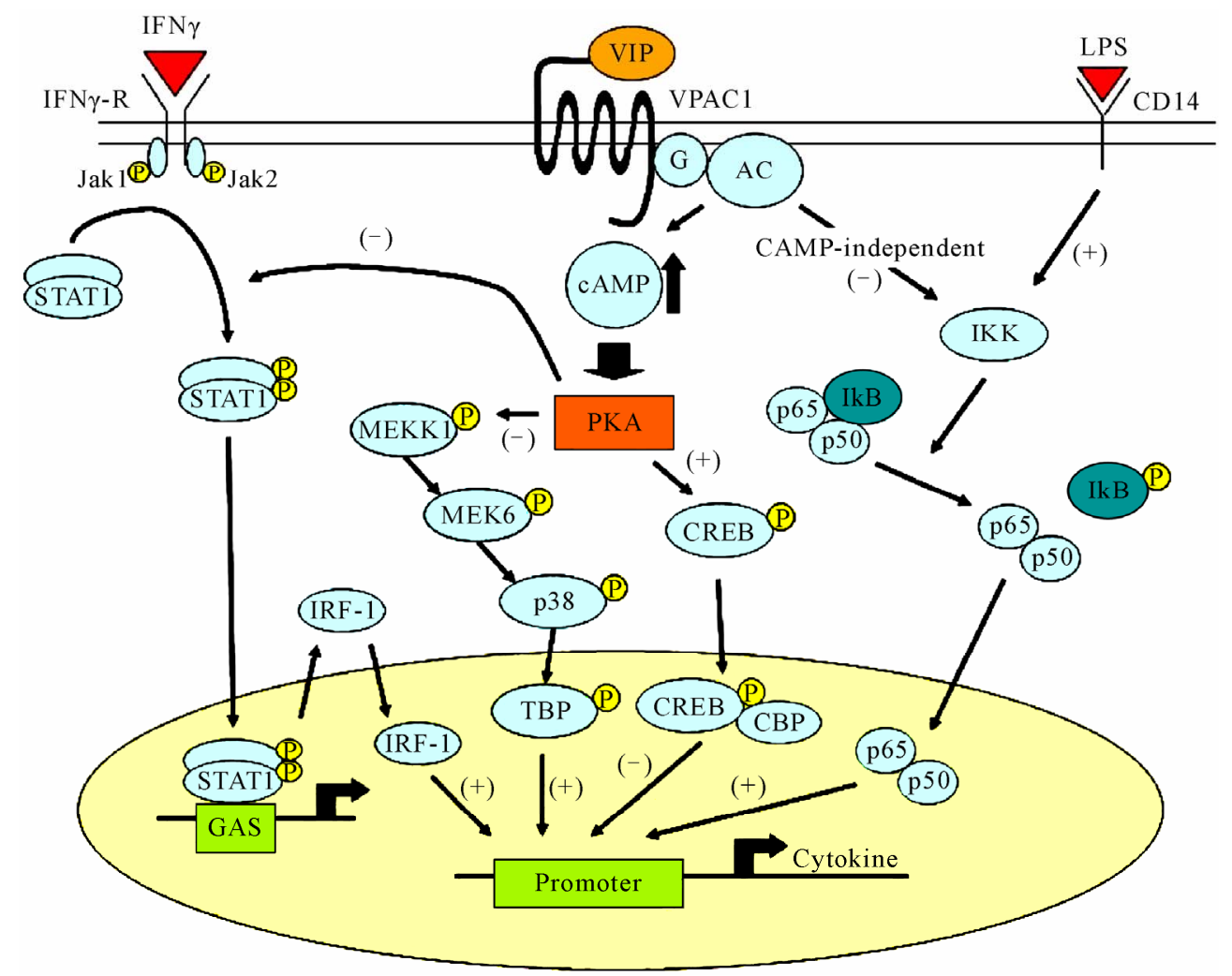

Figure 6. Pathway of VIP signal transduction and inflammatory-response regulation. 
shows a graphical representation of VIP signal transmission and the expected regulatory activity of the inflamematory reactions $[47,48]$.

\section{Conclusions}

We have discussed the structure and functions of VIP and the VPACs and included the latest findings. Further detailed investigations are required to develop a VIP analog that will be appropriate for treating pathological conditions and diseases.

\section{REFERENCES}

[1] S. I. Said and V. Mutt, "Polypeptide with Broad Biological Activity: Isolation from Small Intestine," Science, Vol. 169, No. 951, 1970, pp. 1217-1218. doi:10.1126/science.169.3951.1217

[2] L. Dickson, K. Finlayson, VPAC and PAC Receptors, "From Ligands to Function," Pharmacology \& Therapeutics, Vol. 121, No. 3, 2009, pp. 294-316. doi:10.1016/j.pharmthera.2008.11.006

[3] J. Fahrenkrug, "VIP and PACAP," Results and Problems in Cell Differentiation, Vol. 50, 2010, pp. 294-316. doi:10.1007/400 200924

[4] D. C. Fry, V. S. Madison, D. R. Bolin, et al., "Solution Structure of an Analogue of Vasoactive Intestinal Peptide as Determined by Two-Dimensional NMR and Circular Dichroism Spectroscopies and Constrained Molecular Dynamics," Biochemistry, Vol. 28, No. 6, 1989, pp. 2399-2409. doi:10.1021/bi00432a010

[5] S. Domschke, W. Domschke, S. R. Bloom, et al., "Vasoactive Intestinal Peptide in Man: Pharmacokinetics, Metabolic and Circulatory Effects," Gut, Vol. 19, No. 11, 1978, pp. 1049-1053. doi:10.1136/gut.19.11.1049

[6] C. D. Ulrich II, M. Holtmann and L. J. Miller, "Secretin and Vasoactive Intestinal Peptide Receptors: Members of a Unique Family of G Protein Coupled Receptors," Gastroenterology, Vol. 114, No. 2, 1998, pp. 382-397. doi:10.1016/S0016-5085(98)70491-3

[7] A. J. Harmar, A. Arimura, I. Gozes, et al., "International Union of Pharmacology. XVIII. Nomenclature of Receptors for Vasoactive Intestinal Peptide and Pituitary Adenylate Cyclase-Activating Polypeptide," Pharmacological Reviews, Vol. 50, No. 2, 1998, pp. 265-270.

[8] S. P. Sreedharan, J. X. Huang, M. C. Cheung, et al., "Structure, Expression, and Chromosomal Localization of the Type I Human Vasoactive Intestinal Peptide Receptor Gene," Proceedings of the National Academy of Sciences of the United States of America, Vol. 92, No. 7, 1995, pp. 2939-2943. doi:10.1073/pnas.92.7.2939

[9] M. Svoboda, M. Tastenoy, J. V. Rampelbergh, et al., "Molecular Cloning and Functional Characterization of a Human VIP Receptor from SUP-T1 Lymphoblasts," Biochemical and Biophysical Research Communications, Vol. 205, No. 3, 1994, pp. 1617-1624. doi:10.1006/bbrc. 1994.2852
[10] T. Ishihara, R. Shigemoto, K. Mori, et al., "Functional Expression and Tissue Distribution of a Novel Receptor for Vasoactive Intestinal Polypeptide," Neuron, Vol. 8, No. 4, 1992, pp. 811-819.

doi:10.1016/0896-6273(92)90101-I

[11] E. M. Luts, W. J. Sheward, K. M. West, et al. "The VIP2 Receptor: Molecular Characterization of a cDNA Encoding a Novel Receptor for Vasoactive Intestinal Peptide,' FEBS, Vol. 334, 1993, pp. 3-8. doi:10.1016/0014-5793(93)81668-P

[12] N. Inagaki, H. Yoshida, M. Mizuta, et al., "Cloning and Functional Characterization of a Third Pituitary Adenylate Cyclase-Activating Polypeptide Receptor Subtype Expressed in Insulin-Secreting Cells," Proceedings of the National Academy of Sciences, Vol. 91, No. 7, 1994, pp. 2679-2683. doi:10.1073/pnas.91.7.2679

[13] T. Ito, W. Hou, H. Katuno, et al., "Rat and Guinea Pig Pancreatic Acini Possess Both VIP1 and VIP2 Receptors, which Mediate Enzyme Secretion," American journal of physiology Gastrointestinal and liver physiology, Vol. 278, No. 1, 2000, pp. G64-G74.

[14] B. M. Bissonnette, M. J. Collen, H. Adachi, et al., "Receptors for Vasoactive Intestinal Peptide and Secretin on Rat Pancreatic Acini," American Journal of Physiology, Vol. 246, No. 6, 1984, pp. G710-G717.

[15] G. J. Dockray, "Vasoactive Intestinal Polypeptide and Related Peptides," In: J. H. Walsh and G. J. Dockray, Eds., Raven Press, New York, 1994, pp 447-472.

[16] J. C. Reubi, U. Laderach, B. Waser, et al., "Vasoactive Intestinal Peptide/Pituitary Adenylate Cyclase-Activating Receptor Subtypes in Human Tumors and Their Tissues of Origin," Cancer Research, Vol. 60, No. 11, 2000, pp. 3105-3112.

[17] T. B. Usdin, T. I. Bonner and E. Mesey, "Two Receptors for Vasoactive Intestinal Polypeptide with Similar Specificity and Complementary Distributions," Endocrinology, Vol. 135, No. 6, 1994, pp. 2662-2680. doi:10.1210/en.135.6.2662

[18] H. Igarashi, T. Ito, W. Hou, et al., "Elucidation of Vasoactive Intestinal Peptide Pharmacophore for VPAC1 Receptors in Human, Rat, and Guinea Pig," Journal of Pharmacology and Experimental Therapeutics, Vol. 301, No. 1, 2002, pp. 37-50. doi:10.1124/jpet.301.1.37

[19] H. Igarashi, T. Ito, S. A. Mantey, et al., "Development of Simplified Vasoactive Intestinal Peptide Analogs with Receptor Selectivity and Stability for Human Vasoactive Intestinal Peptide/Pituitary Adenylate Cyclase-Activating Polypeptide Receptors," Journal of Pharmacology and Experimental Therapeutics, Vol. 315, No. 1, 2005, pp. 370-381. doi:10.1124/jpet.105.088823

[20] H. H. Leuchte, C. Baezner, R. A. Baumgartner, et al., "Inhalation of Vasoactive Intestinal Peptide in Pulmonary Hypertension," European Respiratory Journal, Vol. 32, No. 5, 2008, pp. 1289-1294. doi:10.1183/09031936.00050008

[21] M. S. Winzell and B. Ahren, "Role of VIP and PACAP in 
Islet Function," Peptides, Vol. 28, No. 9, 2007, pp. 18051813.doi:10.1016/j.peptides.2007.04.024

[22] W. K. Samson, S. I. Said, J. W. Graham, et al., "Vasoactive Intestinal Polypeptide Concentrations in Median Eminence of Hypothalamus," Lancet, Vol. 2, No. 8095, 1978, pp. 901-902. doi:10.1016/j.peptides.2007.04.024

[23] D. Romano, K. Magalon, A. Ciampini, et al., "Differential Involvement of the Ras and Rap1 Small GTPases in Vasoactive Intestinal and Pituitary Adenylyl Cyclase Activating Polypeptides Control of the Prolactin Gene," The Journal of Biological Chemistry, Vol. 278, No. 51, 2003, pp. 51386-51394. doi:10.1074/jbc.M308372200

[24] B. Baranowska, M. Radzikowska, E. Wasilewska-Dziubinska, et al., "The Role of VIP and Somatostatin in the Control of GH and Prolactin Release in Anorexia Nervosa and in Obesity," Annals of the New York Academy of Sciences, Vol. 921, 2000, pp. 443-455. doi:10.1111/j.1749-6632.2000.tb07013.x

[25] D. Pozo, M. Delgado, C. Martinez, et al., "Immunobiology of Vasoactive Intestinal Peptide (VIP)," Immunology Today, Vol. 21, No. 1, 2000, pp. 7-11. doi:10.1016/S0167-5699(99)01525-X

[26] M. Delgado, E. J. Munoz-Elias, R. P. Gomariz, et al., "Vasoactive Intestinal Peptide and Pituitary Adenylate Cyclase-Activating Polypeptide Prevent Inducible Nitric Oxide Synthase Transcription in Macrophages by Inhibiting NF-Kappa B and IFN Regulatory Factor 1 Activation," The Journal of Immunology, Vol. 162, No. 8, 1999, pp. 4685-4696.

[27] M. Delgado, C. Abad, C. Martinez, et al., "Vasoactive Intestinal Peptide Prevents Experimental Arthritis by Downregulating both Autoimmune and Inflammatory Components of the Disease," Nature Medicine, Vol. 7, No. 5, 2001, pp. 563-568. doi:10.1016/S0167-5699(99)01525-X

[28] M. Delgado, C. Martinez, D. Pozo, et al., "Vasoactive Intestinal Peptide (VIP) and Pituitary Adenylate Cyclase-Activation Polypeptide (PACAP) Protect Mice from Lethal Endotoxemia through the Inhibition of TNF-Alpha and IL-6," The Journal of Immunology, Vol. 162, No. 2, 1999, pp. 1200-1205.

[29] C. Abad, C. Martinez, M. G. Juarranz, et al., "Therapeutic Effects of Vasoactive Intestinal Peptide in the Trinitrobenzene Sulfonic Acid Mice Model of Crohn's Disease," Gastroenterology, 2003, 124, pp. 961-971. doi:10.1053/gast.2003.50141

[30] M. Kojima, T. Ito, T. Oono, et al., "VIP Attenuation of the Severity of Experimental Pancreatitis Is Due to VPAC1 Receptor-Mediated Inhibition of Cytokine Production," Pancreas, Vol. 30, No. 1, 2005, pp. 62-70.

[31] Q. Luo, Y. Wang, D. Feng, et al., "Vasoactive Intestinal Peptide Attenuates Concanavalin A-Mediated Liver Injury," European Journal of Pharmacology, Vol. 607, No. 1-3, 2009, pp. 226-233. doi:10.1016/j.ejphar.2009.02.012

[32] S. Misaka, Y. Aoki, S. Karaki, et al., "Inhalable Powder Formulation of a Stabilized Vasoactive Intestinal Peptide
(VIP) Derivative: Anti-Inflammatory Effect in Experimental Asthmatic Rats," Peptides, Vol. 31, No. 1, 2010, pp. 72-78. doi: 10.1016/j.peptides.2009.09.032

[33] T. Dickinson and S. M. Fleetwood-Walker, "VIP and PACAP: Very Important in Pain?" Trends in Pharmacological Sciences, Vol. 20, No. 8, 1999, pp. 324-329. doi:10.1016/S0165-6147(99)01340-1

[34] L. Edvinsson and R. Uddman, "Neurobiology in Primary Headaches," Brain Research Reviews, Vol. 48, No. 3, 2005, pp. 438-456. doi:10.1016/j.brainresrev.2004.09.007

[35] M. Delgado, N. Varela and E. Gonzalez-Rey, "Vasoactive Intestinal Peptide Protects Against Beta-Amyloid-Induced Neurodegeneration by Inhibiting Microglia Activation at Multiple Levels," Glia, Vol. 56, No. 10, 2008, pp. 1091-1103. doi:10.1002/glia.20681

[36] D. Offen, Y. Sherki, E. Melamed, et al., "Vasoactive Intestinal Peptide (VIP) Prevents Neurotoxicity in Neuronal Cultures: Relevance to Neuroprotection in Parkinson's Disease," Brain Research, Vol. 854, No. 1-2, 2000, pp. 257-262. doi:10.1016/S0006-8993(99)02375-6

[37] M. Delgado and D. Ganea, "Vasoactive Intestinal Peptide Prevents Activated Microglia-Induced Neurodegeneration under Inflammatory Conditions: Potential Therapeutic Role in Brain Trauma," FASEB Journal, Vol. 17, No. 13, 2003, pp. 1922-1924.

[38] J. M. Muller, V. Lelievre, L. Becq-Giraudo, et al., "VIP as a Cell-Growth and Differentiation Neuromodulator Role in Neurodevelopment," Molecular Neurobiology, Vol. 10, No. 2-3, 1995, pp. 115-134. doi:10.1007/BF02740671

[39] A. B. Fernandez-Martinez, A. M. Bajo and A. Valdehita, "Multifunctional Role of VIP in Prostate Cancer Progression in a Xenograft Model: Suppression by Curcumin and COX-2 Inhibitor NS-398," Peptide, Vol. 30, No. 12, 2009, pp. 2357-2364.

[40] T. Moody and I. Gozes, "Vasoactive Intestinal Peptide Receptors: A Molecular Target in Breast and Lung Cancer," Current Pharmaceutical Design, Vol. 13, No. 11, 2007, pp. 1099-1104. doi:10.2174/138161207780619000

[41] S. Jiang, E. Kopras, M. McMichael, et al., "Vasoactive Intestinal Peptide (VIP) Stimulates in Vitro Growth of VIP-1 Receptor-Bearing Human Pancreatic Adenocarcinoma-Derived Cells," Cancer Research, Vol. 57, No. 8, 1997, pp. 1475-1480.

[42] K. Zhang, M. R. Aruva and N. Shanthly, "PET Imaging of VPAC1 Expression in Experimental and Spontaneous Prostate Cancer," Journal of Nuclear Medicine, Vol. 49 , No. 1, 2008, pp. 112-121. doi:10.2967/jnumed.107.043703

[43] M. Calafat, L. Larocca, V. Roca, et al., "Vasoactive Intestinal Peptide Inhibits TNF-Alpha-Induced Apoptotic Events in Acinar Cells from Nonobese Diabetic Mice Submandibular Glands," Arthritis Research Therapy, Vol. 11, No. 2, 2009, p. R53. doi:10.1186/ar2671

[44] A. Castorina, A. Tiralongo, S. Giunta, et al., "PACAP and VIP Prevent Apoptosis in Schwannoma Cells," Brain 
Research, Vol. 1241, 2008, pp. 29-35. doi:10.1016/j.brainres.2008.09.035

[45] A. Linden, L. Hansson, A. Andersson, et al., "Bronchodilation by an Inhaled VPAC2 Receptor Agonist in Patients with Stable Asthma," Thorax, Vol. 58, No. 3, 2003, pp. 217-221. doi:10.1136/thorax.58.3.217

[46] A. Prasse, G. Zissel, N. Lutzen, et al., "Inhaled Vasoactive Intestinal Peptide Exerts Immunoregulatory Effects in Sarcoidosis," American Journal of Respiratory and Critical Care Medicine, Vol. 182, No. 4, 2010, pp. 540548. doi:10.1164/rccm.200909-14510C
[47] M. Delgado, D. Pozo and D. Ganea, "The Significance of Vasoactive Intestinal Peptide in Immunomodulation," Pharmacological Reviews, Vol. 56, 2004, pp. 249-290. doi:10.1124/pr.56.2.7

[48] S. G. Smalley, P. A. Barrow and N. Foster, "Immunomodulation of Innate Immune Responses by Vasoactive Intestinal Peptide (VIP): Its Therapeutic Potential in Inflammatory Disease," Clinical \& Experimental Immunology, Vol. 157, No. 2, 2009, pp. 225-234. doi:10.1111/j.1365-2249.2009.03956.x 